\title{
First Dye-Decolorizing Peroxidase from an Ascomycetous Fungus Secreted by Xylaria grammica
}

\author{
Virginia Kimani ${ }^{1,2}{ }^{\circledR}$, René Ullrich ${ }^{1}{ }^{\circledR}$, Enrico Büttner ${ }^{1}$, Robert Herzog ${ }^{1}$, Harald Kellner ${ }^{1}$, Nico Jehmlich ${ }^{3}{ }^{\oplus}$, \\ Martin Hofrichter ${ }^{1}$ (D) and Christiane Liers ${ }^{1, *(D)}$ \\ 1 Unit of Environmental Biotechnology, International Institute Zittau, Dresden University of Technology, \\ Markt 23, 02763 Zittau, Germany; virwkim@gmail.com (V.K.); rene.ullrich@tu-dresden.de (R.U.); \\ enrico.buettner@tu-dresden.de (E.B.); robert.herzog@tu-dresden.de (R.H.); \\ harald.kellner@tu-dresden.de (H.K.); martin.hofrichter@tu-dresden.de (M.H.) \\ 2 Kenya Industrial Research and Development Institute, Nairobi P.O. Box 30650-00100, Kenya \\ 3 Helmholtz-Centre for Environmental Research-UFZ, Department of Molecular System Biology, \\ 04318 Leipzig, Germany; nico.jehmlich@ufz.de \\ * Correspondence: christiane.liers@tu-dresden.de; Tel.: +49-3583-6124154
}

check for updates

Citation: Kimani, V.; Ullrich, R.; Büttner, E.; Herzog, R.; Kellner, H.; Jehmlich, N.; Hofrichter, M.; Liers, C. First Dye-Decolorizing Peroxidase from an Ascomycetous Fungus Secreted by Xylaria grammica. Biomolecules 2021, 11, 1391. https:// doi.org/10.3390/biom11091391

Academic Editors: Grzegorz Janusz, Daniel Kracher and Anna Pawlik

Received: 7 August 2021

Accepted: 17 September 2021

Published: 21 September 2021

Publisher's Note: MDPI stays neutral with regard to jurisdictional claims in published maps and institutional affiliations.

Copyright: (c) 2021 by the authors. Licensee MDPI, Basel, Switzerland. This article is an open access article distributed under the terms and conditions of the Creative Commons Attribution (CC BY) license (https:/ / creativecommons.org/licenses/by/ $4.0 /)$.

\begin{abstract}
Background: Fungal DyP-type peroxidases have so far been described exclusively for basidiomycetes. Moreover, peroxidases from ascomycetes that oxidize $\mathrm{Mn}^{2+}$ ions are yet not known. Methods: We describe here the physicochemical, biocatalytic, and molecular characterization of a DyP-type peroxidase (DyP, EC 1.11.1.19) from an ascomycetous fungus. Results: The enzyme oxidizes classic peroxidase substrates such as 2,6-DMP but also veratryl alcohol and notably $\mathrm{Mn}^{2+}$ to $\mathrm{Mn}^{3+}$ ions, suggesting a physiological function of this DyP in lignin modification. The $\mathrm{K}_{\mathrm{M}}$ value $(49 \mu \mathrm{M})$ indicates that $\mathrm{Mn}^{2+}$ ions bind with high affinity to the $\mathrm{XgrDyP}$ protein but their subsequent oxidation into reactive $\mathrm{Mn}^{3+}$ proceeds with moderate efficiency compared to MnPs and VPs. $\mathrm{Mn}^{2+}$ oxidation was most effective at an acidic $\mathrm{pH}$ (between 4.0 and 5.0) and a hypothetical surface exposed an $\mathrm{Mn}^{2+}$ binding site comprising three acidic amino acids (two aspartates and one glutamate) could be localized within the hypothetical $\mathrm{XgrDyP}$ structure. The oxidation of $\mathrm{Mn}^{2+}$ ions is seemingly supported by four aromatic amino acids that mediate an electron transfer from the surface to the heme center. Conclusions: Our findings shed new light on the possible involvement of DyP-type peroxidases in lignocellulose degradation, especially by fungi that lack prototypical ligninolytic class II peroxidases.
\end{abstract}

Keywords: dye-decolorizing peroxidase; Xylaria grammica; ascomycete; $\mathrm{Mn}^{2+}$ oxidation; $\mathrm{Mn}^{2+}$ binding site

\section{Introduction}

Peroxidases of the DyP-type or more shortly DyPs (dye-decolorizing peroxidases, EC 1.11.1.19) were first reported in 1995 for cultures of Bjerkandera adusta (originally described as a strain of Geotrichum candidum [1,2]). Later, DyPs were recognized as a new family of heme peroxidases found in both fungi and bacteria. Thus, there are features in the secondary and tertiary structure of DyPs that do not allow them to be classified into any of the known peroxidase groups of bacteria, fungi, or plants (class I, II, and III peroxidases/PODs, respectively). Sequence similarities to ligninolytic class II peroxidases are low (0.5-5\%) and the typical heme-binding region, which is conserved among the whole catalase-peroxidase superfamily, does not contain the distal His [3-5]. All DyPs contain a highly conserved GXXDG motif, and the distal His is replaced by an aspartate (Asp) as an acid-base catalyst, which is assisted in proton acceptation and charge stabilization by an Arg [6].

Since their discovery, nine fungal DyPs (from among others Mycetinis scorodonius (MscDyP), [7]; Auricularia auricula-judae (AauDyP1, AauDyP2), [8]; Exidia glandulosa (EglDyP), 
Mycena epipterygia (MepDyP), [9]) and fifteen bacterial enzymes (e.g., from Thermobifidia fusca, [10]; Rhodococcus jostii, [11]) have been described. Among them are eight wild-type proteins and three recombinant enzymes (one from A. auricula judae (rAauDyP) and two from Pleurotus ostreatus (rPosDyP), [12]). Wild-type proteins (e.g., AauDyP1 and 2) can be produced in complex plant-based media such as diluted tomato juice or soybean meal suspension with or without the addition of 'elicitors' (e.g., guaiacol or $\beta$-carotene). Activity levels range from 100 to $8000 \mathrm{U} \mathrm{L}^{-1}$ (corresponding to 0.25 to $20 \mathrm{mg} \mathrm{L}^{-1}$ DyP protein, [8,9]). The production of recombinant fungal DyPs, e.g., of rBadDyP in Aspergillus oryzae or of $\mathrm{r}$ Aau DyP and $\mathrm{rPosDyP}$ in Escherichia coli, has facilitated the performance of mutational studies, increasing our understanding of the relationship between DyP structure and function [12-15]. So far, only three fungal DyPs (from B. adusta, A. auricula-judae and P. ostreatus) have been thoroughly characterized from the structural and mechanistic point of view [6,12-18].

DyPs oxidize a range of substrates, notably recalcitrant azo and anthraquinone dyes (e.g., Reactive Blue5, [2,9]), phenols (e.g., methoxy- and nitrophenols, [9,17]), terpenoids (e.g., $\beta$-carotene, [7]), non-phenolic aromatics (e.g., trimethoxybenzene, veratryl alcohol, [9]) and even the lignin model dimer 'adlerol' $[8,9,15]$. The oxidation of non-phenolic aromatics and adlerol works best at rather low $\mathrm{pH}$ (i.e., $\mathrm{pH}<3.0,[5,8,9]$ ). The specific activity of DyP towards adlerol at $\mathrm{pH} 3.0$ was found to be one order of magnitude lower than that of $\mathrm{LiP}$ (lignin peroxidase) of Phanerochaete chrysosporium, but demonstrates that in theory, it may have the capacity to oxidize lignin or lignin-like molecules [9].

Furthermore, a few bacterial DyPs (e.g., RjoDyP, [11]) and one recombinant fungal DyP (rPosDyP4) were found to oxidize $\mathrm{Mn}^{2+}$ into $\mathrm{Mn}^{3+}$, an exclusive catalytic feature of manganese (MnPs) and versatile peroxidases (VP) [5]. Indeed, for one recombinant bacterial DyP from $R$. jostii, it has been shown that $\mathrm{Mn}^{2+}$ oxidation is involved in the oxidation and partial breakdown of adlerol $\left(k_{\mathrm{cat}}=7.4 \times 10^{-3} ;[11]\right)$ - a convincing indication for the possible involvement of DyPs in lignin oxidation.

The physicochemical properties of fungal DyPs resemble those of class II PODs. They are glycosylated proteins (up to $20 \%$ sugars) that show a Soret band at $405-407 \mathrm{~nm}$, reflecting the proximal heme-imidazole (His) ligation. Molecular weights of DyPs range between 40 and $67 \mathrm{kDa}$ with isoelectric points (pI) between 3.5 and 4.3 [5]. According to the InterPro database (http:/ / www.ebi.ac.uk/interpro/ accessed on 18 September 2021), the DyP family currently comprises over 5019 hypothetical proteins, of which 4886 are from bacteria, 122 from eukaryotes, and 11 from archaea [19], confirming their ubiquitous distribution but also the dominance of bacterial DyPs. Consequently, van Bloois and colleagues [20] suggested renaming the DyP family as the 'bacterial heme peroxidase' family. However, this suggestion was not accepted by the scientific community [21].

According to similarities in the primary structure (i.e., sequence homology), DyPs can be phylogenetically categorized in four classes/subfamilies [22]. Classes A, B, and C correspond to DyPs of prokaryotic origin (e.g., class A-T. fusca DyP, class B-Schewanella oneidenis DyP, class C-Anabaena and Amycolatopsis DyP); fungal DyPs (those belonging to the basidio- and ascomycetes) cluster only within class $\mathrm{D}$ and show between 7 to $16 \%$ homology to the three bacterial classes [21]. To overcome the ambiguity of DyP categorization, especially regarding classes $C$ and $D$, a new classification has been proposed by Yoshida and Sugano [21]. It distinguishes between primitive (P), intermediate (I), and advanced $(\mathrm{V})$ clades depending on both primary and particularly tertiary structure homologies. The $\mathrm{V}$ clade now includes the former classes $\mathrm{C}$ and $\mathrm{D}$ since both protein subfamilies appear to be more closely related according to structural homologies.

Although the DyP-catalyzed oxidation of lignin model compounds (adlerol, methoxybenzenes, $[8,9])$ and the enhancement of enzymatic straw hydrolysis by Irpex lacteus DyP [23] have been proven, the natural function of these enzymes remains unclear [15]. Interestingly, Sugawara et al. [24] have recently reported that a DyP of Bjerkandera adusta is produced and secreted in response to alizarin, an anti-fungal anthraquinone compound produced by the plant Rubia tinctorum (common madder). This indicates that DyPs could 
be part of the biochemical defense of fungi against toxic plant and microbial metabolites. The widespread occurrence of DyPs in forest soils (which has been shown at the transcript and activity levels) may support this assumption [25].

In the present study, we describe for the first time an $\mathrm{Mn}^{2+}$-oxidizing DyP-type peroxidase secreted by an ascomycetous fungus, a new strain of Xylaria grammica (IHIA82, GenBank accession number MK408621) collected from rotting plant debris in the Kakamega Forest National Reserve (Kenya; lat 0.33431, long 34.87814). The genome of this strain was sequenced with a total size of $47.0 \mathrm{Mbp}$ and 12,126 predicted genes [26].

\section{Materials and Methods}

\subsection{Screening and Production of a DyP-Type Peroxidase by X. grammica}

For the production of the DyP-type peroxidases from X. grammica, liquid cultivation was performed using a glucose-peptone medium (SPM; glucose $28 \mathrm{~g} \mathrm{~L}^{-1}$, malt extract $3 \mathrm{~g} \mathrm{~L}^{-1}$, soy-peptone $12 \mathrm{~g} \mathrm{~L}^{-1}$, yeast extract $3 \mathrm{~g} \mathrm{~L}^{-1}$ ), which is known to stimulate the secretion of certain fungal enzymes $[27,28]$. A complete fungal pre-culture grown on malt-extract agar (MA) was homogenized in a $100 \mathrm{~mL}$ Erlenmeyer flask containing $80 \mathrm{~mL}$ sterile water using an Ultra-Turax ${ }^{\mathrm{TM}}$ device; $9 \mathrm{~mL}$ of this homogenized suspension was transferred with a sterile pipette to $500 \mathrm{~mL}$ culture flasks containing $200 \mathrm{~mL}$ of the SPM. After inoculation, the cultures were agitated on a rotary shaker at $100 \mathrm{rpm}$ and $23^{\circ} \mathrm{C}$. Enzyme activities $\left(\mathrm{Mn}^{2+}\right.$-independent peroxidase activities) and $\mathrm{pH}$ were determined every 2-3 days over a total cultivation period of three weeks. Later, the production of DyP from X. grammica was performed on a larger scale in 500 and $1000 \mathrm{~mL}$ flasks containing 200 or $1000 \mathrm{~mL}$ of the SPM medium, respectively.

\subsection{Enzyme Assays}

During fungal cultivation, activities of an $\mathrm{Mn}^{2+}$-independent peroxidase (MiP) were measured to determine the most appropriate time for harvesting the cultures. All activity measurements were performed, after removing the fungal mycelium by centrifugation, in $1 \mathrm{~mL}$ cuvettes at room temperature using a Cary $50 \mathrm{UV} /$ Vis spectrophotometer (Varian, Darmstadt, Deutschland), and the enzymatic activities were calculated in units. One unit is defined as that amount of enzyme that catalyzes the conversion or formation of $1 \mu \mathrm{mol}$ substrate or product, respectively, per minute $\left(\mu \mathrm{mol} \mathrm{min}{ }^{-1}\right)$.

To determine MiP activity, ABTS ( $0.3 \mathrm{mM}$ final concentration) oxidation was followed in $50 \mathrm{mM}$ sodium citrate buffer $(\mathrm{pH} \mathrm{4.5)}$ in the absence (for laccase) or presence of $\mathrm{H}_{2} \mathrm{O}_{2}(0.1 \mathrm{mM}$ for MiP). Formation of the product was monitored at $420 \mathrm{~nm}$ $\left(\varepsilon_{420}=36 \mathrm{mM}^{-1} \mathrm{~cm}^{-1},[8,29]\right)$. Phenol-oxidizing activity using 2,6-dimethoxyphenol (2,6-DMP; $\left.\varepsilon_{469}=27.5 \mathrm{mM}^{-1} \mathrm{~cm}^{-1}\right)$ and the oxidation of synthetic dyes with Reactive Blue 5 (RBlue5, $\varepsilon_{598}=8.0 \mathrm{mM}^{-1} \mathrm{~cm}^{-1}$ ) was measured in sodium citrate buffer ( $50 \mathrm{mM}$, pH 4.5) [9]. The oxidation of $\mathrm{Mn}^{2+}$ to $\mathrm{Mn}^{3+}$ was used to determine the manganese-dependent activity of the X. grammica peroxidase (manganese-oxidizing activities in fungal cultures are mainly due to MnP (EC 1.11.1.13) but may be also caused by VP (EC 1.11.1.16)) [30]. The formation of $\mathrm{Mn}^{3+}$-malonate complexes was monitored in the presence of $\mathrm{MnCl}_{2}(0.5 \mathrm{mM}$ final concentration) in $50 \mathrm{mM}$ sodium malonate buffer ( $\mathrm{pH} 4.5)$ by measuring the initial increase in absorbance at $270 \mathrm{~nm}\left(\varepsilon_{270}=11.5 \mathrm{mM}^{-1} \mathrm{~cm}^{-1}\right)$ after addition of $\mathrm{H}_{2} \mathrm{O}_{2}(0.1 \mathrm{mM}$ final concentration). Veratryl alcohol (VA, $\varepsilon_{270}=9.3 \mathrm{mM}^{-1} \mathrm{~cm}^{-1}$ ) oxidizing activity was measured in sodium tartrate buffer $(50 \mathrm{mM}, \mathrm{pH} 3.0)$ in the presence of $\mathrm{H}_{2} \mathrm{O}_{2}(0.1 \mathrm{mM}$ final concentration) [9].

\subsection{Purification of the DyP from $X$. grammica (XgrDyP)}

After reaching maximal activities, the culture liquids were harvested. The fungal mycelium was removed by filtration and the crude liquid was frozen at $-20{ }^{\circ} \mathrm{C}$ prior to purification to remove polysaccharides by precipitation. After thawing, the crude enzyme liquid was again filtered at $11^{\circ} \mathrm{C}$ (GF6, Sartorious $\mathrm{GmbH}$, Göttingen, Deutschland) followed by ultrafiltration and dialysis steps using a tangential flow cassette (Vivaflow 200, 
cut-off 10 kDa; Sartorius, Göttingen, Germany). All chromatographic steps were performed with ÄKTA ${ }^{\mathrm{TM}}$ Avant FPLC systems (GE Healthcare, Chicago, IL, USA). Absorbing material eluting from the columns was simultaneously monitored at $280 \mathrm{~nm}$ (total protein) and $405 \mathrm{~nm}$ (heme proteins including DyP).

The crude peroxidase preparation of X. grammica (XgrDyP) was purified by four steps of FPLC using anion exchange chromatography (AEX) and size exclusion chromatography (SEC) for separation. In the first and second steps, the concentrated crude enzyme was applied to a Q-Sepharose $(26 \times 100 \mathrm{~mm})$ column and eluted with a linear gradient of 0-1.0 M NaCl in $10 \mathrm{mM}$ sodium acetate buffer $(\mathrm{pH} 6.0)$ at a flow rate of $13 \mathrm{~mL} \mathrm{~min}^{-1}$ and with a fraction size of $7.0 \mathrm{~mL}$. Peroxidase-positive fractions were loaded onto an SEC column HiLoad 26/600 Superdex 75 PG equilibrated with $50 \mathrm{mM}$ sodium acetate buffer (pH 6.75) containing $0.1 \mathrm{M} \mathrm{NaCl}$. Enzyme protein was eluted with the same buffer at a flow rate of $2.5 \mathrm{~mL} / \mathrm{min}^{-1}$. The third step was performed on a MonoQ column $(5 \times 50 \mathrm{~mm})$ with a $\mathrm{NaCl}$ gradient of $0-0.4 \mathrm{M}$ in $10 \mathrm{mM}$ sodium acetate ( $\mathrm{pH}$ 6.0) and with a fraction size of $1.5 \mathrm{~mL}$ at a flow rate of $6 \mathrm{~mL} \mathrm{~min}^{-1}$. The last step was a re-chromatograhic elution of the peroxidase-positive fractions originating from the previous AEX separations. The parameters were the same as already described, except that the loading and elution buffers were adjusted to $\mathrm{pH} 5.8$ and 6.0, respectively. Fractions containing XgrDyP activity were pooled, concentrated, and washed with $10 \mathrm{mM}$ sodium acetate buffer ( $\mathrm{pH}$ 6.5).

\subsection{Protein Determination}

Total protein of crude extracts and of each purification step were determined using the method of Bradford [31] with a Roti ${ }^{\circledR}$ Nanoquant Kit (Roth, Karlsruhe, Germany) and bovine serum albumin (BSA) as protein standards. Samples were pipetted into a 96-well microtiter plate in triplicate and the absorbance was measured at 590/450 nm with a microplate reader (Infinite 200, Tecan, Switzerland).

\subsection{Protein Electrophoresis}

SDS-PAGE was performed according to the protocol described in [32] with a vertical electrophoresis system (XCell SureLock ${ }^{\mathrm{TM}}$ Mini-Cell, Invitrogen, Carlsbad, CA, USA) and Novex ${ }^{\circledR}$ NuPAGE ${ }^{\circledR} 12 \%$ Bis-Tris Gels (Invitrogen, Waltham, MA, USA). This electrophoresis method was applied to check the protein purity under denaturing conditions and to determine the molecular weight of the purified enzymes. A low-MW protein mixture was used as standard (MBI Fermentas, St. Leon-Rot, Germany). Electrophoretically separated proteins were visualized by using a Colloidal Blue Staining Kit (Invitrogen, Waltham, MA, USA).

The above-mentioned electrophoresis system was also used to separate proteins according to their isoelectric points (pIs). Electrophoresis was performed according to the manufacturer's protocol with Novex ${ }^{\circledR}$ Vertical IEF Gels (pH gradient 3-7; Invitrogen, Waltham, MA, USA) and a Liquid Mix IEF Marker ( $\mathrm{pH}$ 3.0-10.0; Serva, Heidelberg, Germany) as a reference. Protein bands in the vertical polyacrylamide gel were afterwards visualized by using a Colloidal Blue Staining Kit (Invitrogen, Waltham, MA, USA).

\subsection{Determination of $p H$-Optima and Stability}

The $\mathrm{pH}$-optimum of $\mathrm{XgrDyP}$ was determined for the oxidation of 2,6-DMP, RBlue5, and $\mathrm{Mn}^{2+}$ ions at $\mathrm{pH}$ values ranging from 2.0 to 7.0 in either sodium citrate buffer for 2,6-DMP and RBlue5 or in sodium malonate buffer $(50 \mathrm{mM})$ for the oxidation of $\mathrm{Mn}^{2+}$ ions. The latter was specifically assayed in the presence of $\mathrm{MnCl}_{2}(0.5 \mathrm{mM})$ by monitoring the formation of $\mathrm{Mn}^{3+}$-malonate complexes at $270 \mathrm{~nm}\left(\varepsilon_{270}=11.3 \mathrm{mM}^{-1} \mathrm{~cm}^{-1}\right.$, [30]). The conversion of DMP $(5 \mathrm{mM})$ was detected at $469 \mathrm{~nm}\left(\varepsilon_{469}=27.5 \mathrm{~cm}^{-1} \mathrm{mM}^{-1}\right.$, [33] $)$ and that of RBlue5 $(0.1 \mathrm{mM})$ at $598 \mathrm{~nm}\left(\varepsilon_{598}=8.0 \mathrm{~cm}^{-1} \mathrm{mM}^{-1}\right.$; [34]). All reactions were started by the addition of $\mathrm{H}_{2} \mathrm{O}_{2}(0.1 \mathrm{mM})$ and followed spectrophotometrically (Cary $50 \mathrm{UV}-\mathrm{Vis}$ spectrophotometer) over appropriate time intervals between 10 and $60 \mathrm{~s}$. 


\subsection{Kinetic Parameters}

Apparent Michaelis-Menten $\left(K_{\mathrm{m}}\right)$ and catalytic constants $\left(k_{\mathrm{cat}}\right)$ of the purified XgrDyP were determined spectrophotometrically for the substrates ABTS, 2,6-DMP, RBlue5, and $\mathrm{Mn}^{2+}$ under the above-mentioned conditions. Lineweaver-Burk plots were made from the initial rates obtained at varying substrate concentrations while the concentration of the co-substrate was held constant.

\subsection{Peptide Sequencing}

To identify the enzyme-encoding gene from the corresponding genomic data of $X$. grammica, analysis of internal peptides ('peptide mapping') of purified XgrDyP was performed at the Helmholtz Center for Environmental Research-UFZ (Department of Molecular Systems Biology, Leipzig, Germany). Proteins were digested from a Comassiestained SDS gel by trypsin and the peptide lysates were analyzed by nano-LC-MS/MS (Supplementary Materials S1: Proteomics (Peptide Mapping)).

\subsection{Phylogenetic Analysis}

After identification of the protein-coding sequences, Blast2GO was used to annotate the proteins and to identify the DyP genes in the Xylaria grammica genome [26].

A multiple protein sequence alignment was calculated using Clustal Omega 1.2.2, embedded in Geneious Prime 2021. The phylogenetic tree was calculated using a maximum likelihood approach with PhyML 3.0 [35]. Branch support was estimated by bootstrapping.

\subsection{Homology Modeling}

Homology modeling of protein 3D structures was performed based on the amino acid sequences of the $\mathrm{XgrDyP}$ gene 488 using the webserver C-I-TASSER [36]. For modeling, the proposed $\mathrm{Mn}^{2+}$ oxidation site, a DyP from P. ostreatus ( $\mathrm{rPosDyP4}$, PDB 6fsk chain A) was used as a template. The resulting protein models were superimposed and adjusted using PyMOL (The PyMOL Molecular Graphics System, Version 2.2.0 Schrödinger, LLC; http://pymol.org/ accessed on 18 September 2021) with the above-mentioned template sequence.

\section{Results}

\subsection{Production and Purification of a DyP from X. grammica}

Small-scale production of MiP reached the highest levels of up to $750 \mathrm{U} \mathrm{L}^{-1}$ during growth in soy-peptone-based complex liquid media. Enzyme secretion was accompanied by alkalization of the medium from $\mathrm{pH} 5.0$ on day 8 to 8.9 on day 20. In parallel, the MiP activity increased from 80 to $750 \mathrm{U} \mathrm{L}^{-1}$. (Figure 1). It should be noted that 'true' extracellular peroxidase activity (neither of DyP nor of any other heme peroxidase) has not yet been described for an ascomycetous fungus. Therefore, the X. grammica peroxidase (XgrDyP) was chosen for further studies regarding enzyme purification and characterization.

Production of $\mathrm{Xgr}$ DyP on a larger scale was performed in $500 \mathrm{~mL}$ flasks containing $200 \mathrm{~mL}$ SPM medium. After reaching a sufficient activity level (up to $2028 \mathrm{U} \mathrm{L}^{-1}$ on day 26 of cultivation; data not shown), the culture liquid was harvested, filtrated, frozen, and stored at $-20{ }^{\circ} \mathrm{C}$ until enzyme purification. The freezing and thawing step allowed the removal of precipitating polysaccharides that were separated by a second filtration step. After the concentration of the crude enzyme was obtained, $\mathrm{XgrDyP}$ was purified by several steps of FPLC using AEX and SEC techniques. 


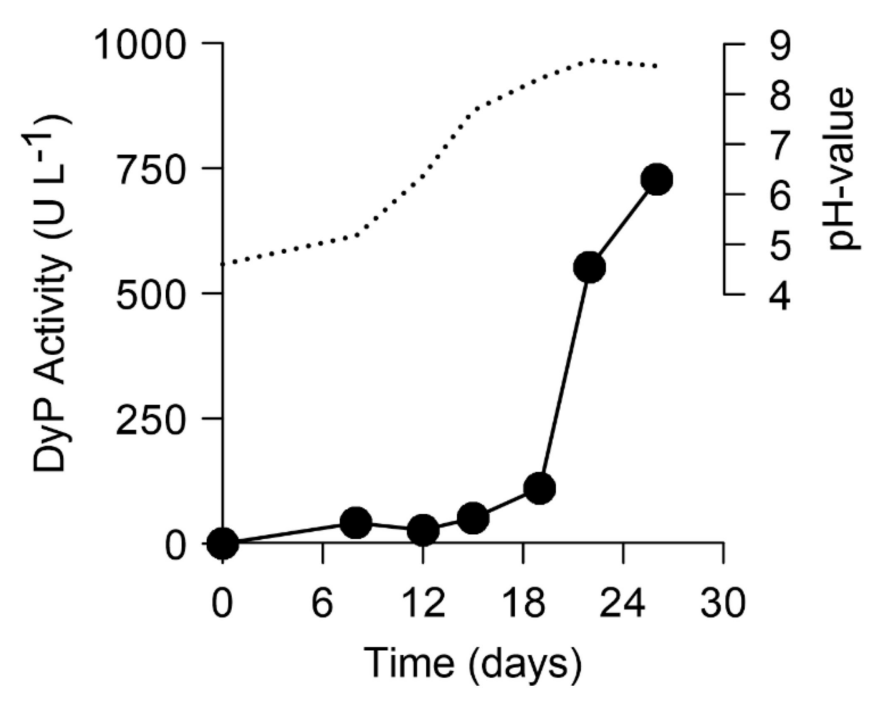

Figure 1. Time course of DyP production (black circles) by X. grammica in SPM medium; activity was measured with ABTS and $\mathrm{H}_{2} \mathrm{O}_{2}$, dotted lines- $\mathrm{pH}$ value.

By using Q-Sepharose as the first separation step, the crude enzyme extract was divided into two fractions: an unbound and a bound fraction. The latter was used for further purification studies. It was re-chromatographed by a second Q-Sepharose step under the same conditions (Q-Sepharose_II) and thus, almost 100\% enzyme recovery (1160 U) could be achieved. In the next step, the fraction with the highest peroxidase activity was loaded on an SEC column. Thereby further protein material was separated from the target protein $(\mathrm{Xgr} \mathrm{DyP})$ without noticeable activity loss, which led to an increase in specific activity from 4.6 to $10.9 \mathrm{U} \mathrm{mg}^{-1}$ (purification factor increased from 1.4 to 3.2; Table 1).

Table 1. Purification of the extracellular peroxidase from X. grammica (XgrDyP).

\begin{tabular}{cccccc}
\hline Purifications Step & $\begin{array}{c}\text { Activity } \\
\text { (U) }\end{array}$ & $\begin{array}{c}\text { Specific Activity } \\
\left(\mathbf{U ~ m g ~}^{-\mathbf{1}}\right)\end{array}$ & $\begin{array}{c}\text { Protein } \\
\text { Amount (mg) }\end{array}$ & Yield (\%) & $\begin{array}{c}\text { Purification } \\
(\mathbf{x}-\mathbf{F o l d})\end{array}$ \\
\hline Culture filtrate & 2028 & 3.4 & 595.7 & 100 & - \\
Ultrafiltrate 10 kDa & 1923 & 3.3 & 584.0 & 95 & 1.0 \\
Q-Sepharose_I & 1175 & 4.4 & 265.2 & 58 & 1.3 \\
Q-Sepharose_II & 1160 & 4.6 & 254.4 & 57 & 1.4 \\
SEC & 1301 & 10.9 & 41.9 & 64 & 3.2 \\
MonoQ_I & 568 & 13.8 & 2.4 & 28 & 4.1 \\
MonoQ_II & 120 & 51.0 & & 6 & 15.0 \\
\hline
\end{tabular}

By using a MonoQ column, the active SEC fraction was divided into two peaks, which was accompanied by an activity loss of approximately $44 \%$ in relation to the preceding step and with a further increase in specific activity (up to $14 \mathrm{U} \mathrm{mg}^{-1}$ ). Immediately following, the fraction with the highest activity was purified to apparent homogeneity by a re-chromatographic step on a MonoQ column under almost identical conditions (except that the $\mathrm{pH}$ was slightly reduced from 6.0 to 5.8; Figure 2).

Finally, a 15-fold purification was achieved along with a moderate activity recovery of $6 \%$ for the homogeneous XgrDyP protein preparation. The final specific activity was $51.0 \mathrm{U} \mathrm{mg}^{-1}$, the Reinheitszahl 1.10 and the residual activity amounted to 120 total units corresponding to approximately $2.4 \mathrm{mg}$ total protein (Table 1 ). 


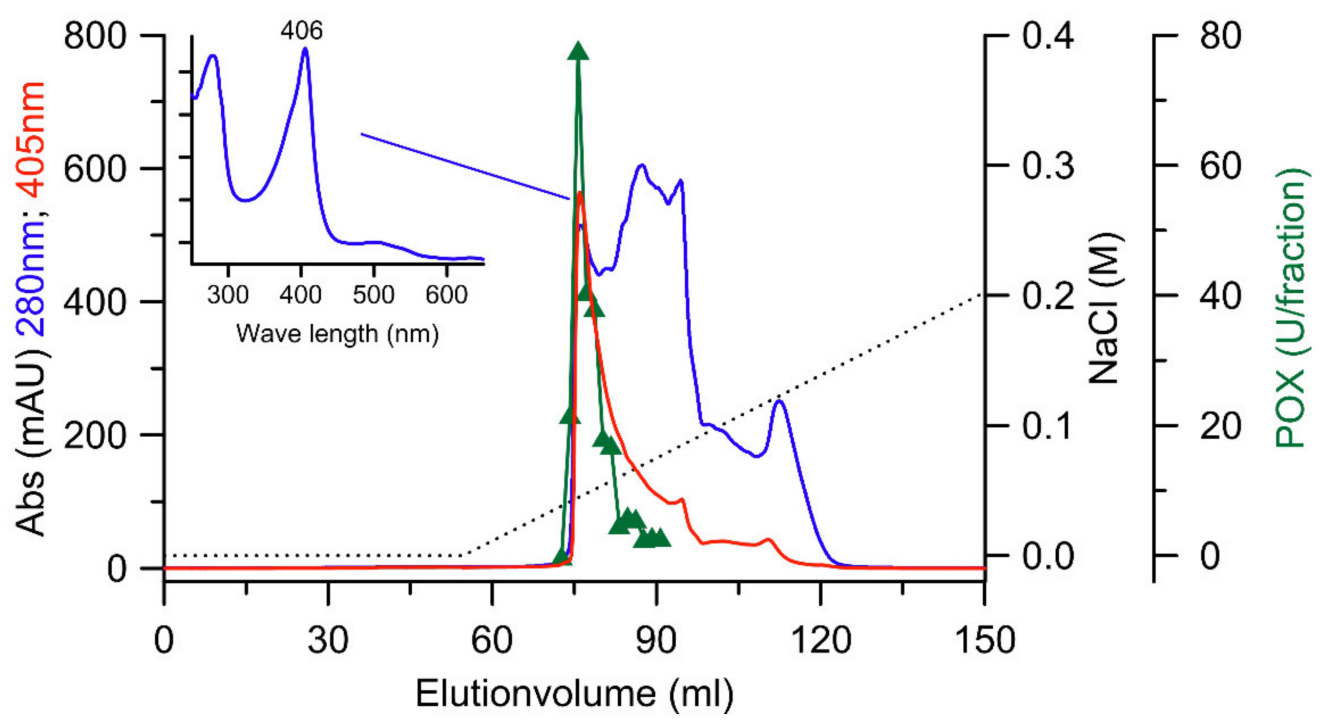

Figure 2. FPLC elution profiles of the last re-chromatographic purification step of XgrDyP using a MonoQ column $(10 \times 100 \mathrm{~mm})$. Absorption (mAU) at $280 \mathrm{~nm}$ (blue $\rightarrow$ total protein) and $405 \mathrm{~nm}$ (red $\rightarrow$ heme), DyP activity (green), $\mathrm{NaCl}$ gradient (dashed line).

\subsection{Characterization of the X. grammica DyP}

Purified $\mathrm{XgrDyP}$ exhibited the characteristic reddish color of heme-containing enzymes and had absorption maxima at 406, 501, and $630 \mathrm{~nm}$ (Figure 3A). The protein appeared as a single protein band with a molecular mass of $49 \mathrm{kDa}$ in the SDS-PAGE gel indicating its pure nature (Figure 3B).

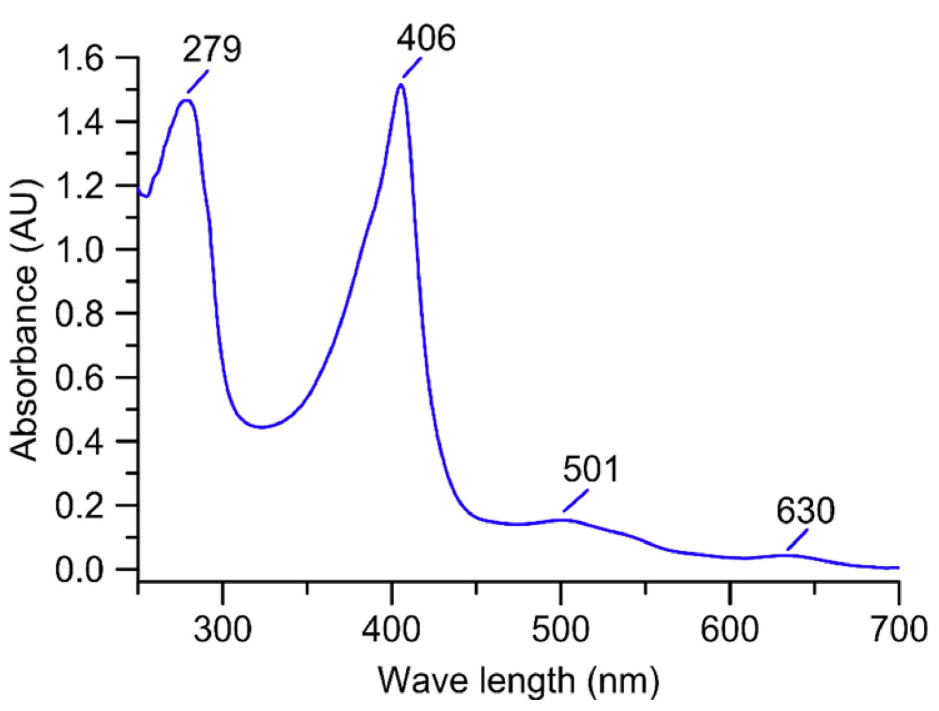

A

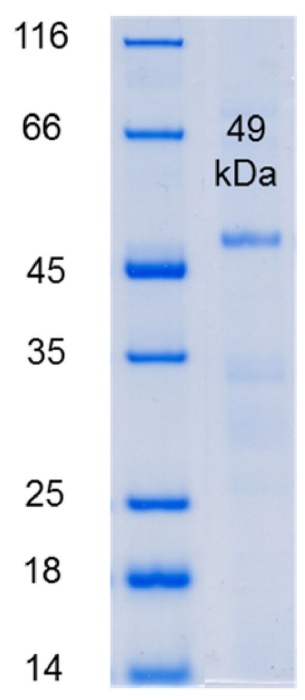

B

Figure 3. (A) UV-Vis absorption spectrum of purified $\mathrm{XgrDyP}$ in its resting state with the Soret band at $406 \mathrm{~nm}$ and additional bands at 279,501 , and $630 \mathrm{~nm}$ representing the $\delta-, \beta-$, and $\alpha$-bands, respectively. (B) SDS-PAGE of the purified X. grammica DyP (XgrDyP; right), left: protein marker.

In addition to typical peroxidase substrates such as heterocyclic ABTS and phenolic 2,6-DMP, $\mathrm{Xgr}$ DyP also oxidized non-phenolic VA (data not shown) and $\mathrm{Mn}^{2+}$ ions. To our best knowledge, the oxidation of the latter substrate has not been reported for any wild-type DyP nor for any ascomyceteous peroxidase. Against this background, the $\mathrm{pH}$ dependencies of $\mathrm{XgrDyP}$ for the oxidation of the classic peroxidase substrate 2,6-DMP, the specific DyP substrate RBlue5, as well as for the 'untypical' DyP substrate $\mathrm{Mn}^{2+}$ were 
determined. The oxidation of the phenolic substrate (2,6-DMP) occurred with a distinct $\mathrm{pH}$ maximum at 3.5 , and with approximately $95 \%$ and $90 \%$ of the maximum activity at $\mathrm{pH} 3.0$ and 4.0, respectively (Figure 4). Above $\mathrm{pH} 4.0$, however, 2,6-DMP oxidation dropped rapidly to $20 \%$ at $\mathrm{pH} 5.0$ and to almost zero at $\mathrm{pH} 6.0$; on the other hand, over $40 \%$ activity remained at $\mathrm{pH}$ 2.0. The $\mathrm{pH}$ optimum of the RBlue 5 oxidation formed a sharper maximum at $\mathrm{pH} 4.0$ but otherwise resembled the 2,6-DMP profile.

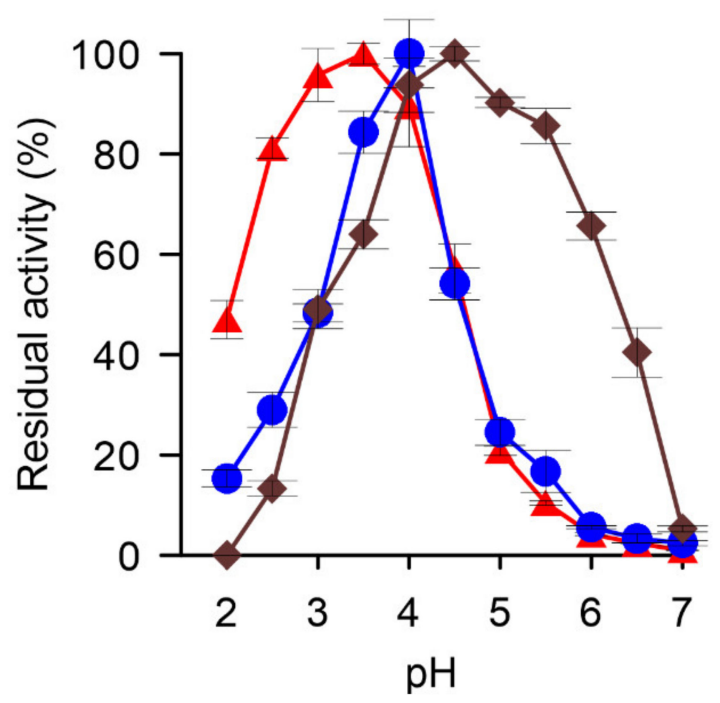

Figure 4. $\mathrm{pH}-\mathrm{Optima}$ for the oxidation of 2,6-DMP (red triangles), RBlue5 (blue circles), and $\mathrm{Mn}^{2+}$ ions (brown squares) by the purified XgrDyP.

The curve for the oxidation of $\mathrm{Mn}^{2+}$ showed a maximum at $\mathrm{pH} 4.5$ and appreciable activities down to $\mathrm{pH} 4.0$ and up to $\mathrm{pH} 5.5$ (80-90\% in relation to the maximal activity). Interestingly, $\mathrm{Mn}^{2+}$ oxidizing activities were still detectable at less optimal $\mathrm{pH}$ above 5.5.

\subsection{Kinetic Parameters of the Purified X. grammica DyP}

The Michaelis-Menten constants $\left(K_{\mathrm{M}}\right)$ for ABTS, 2,6-DMP and RBlue5 were calculated to be 41,12 , and $41 \mu \mathrm{M}$, which is in the range of those of the DyP from A. auriculajudae (AauDyP, [8]). The enzyme showed the highest affinity $\left(K_{\mathrm{m}}=12 \mu \mathrm{M}\right)$ and catalytic efficiency $\left(k_{\mathrm{cat}} / \mathrm{K}_{\mathrm{M}}=2499 \mathrm{~s}^{-1} \mathrm{mM}^{-1}\right)$ for the phenolic substrate 2,6-DMP. The $K_{\mathrm{M}}$ value for the oxidation of $\mathrm{Mn}^{2+}$ ions $(49 \mu \mathrm{M})$ was relatively low (suggesting high affinity to the substrate) compared to recombinant DyPs from P. ostreatus, and interestingly ranged in the same order of magnitude as those of true MnPs and VPs of Pleurotus spp. and other white-rot fungi [12]. On the other hand, the catalytic efficiency and turnover number of $\mathrm{XgrDyP}$ for $\mathrm{Mn}^{2+}$ ions $\left(k_{\mathrm{cat}} / K_{\mathrm{M}}=8.0 \mathrm{~s}^{-1} \mathrm{mM}^{-1}\right.$ and $\left.k_{\mathrm{cat}}=0.4 \mathrm{~s}^{-1}\right)$ were notably lower than the respective data for typical Mn-oxidizing peroxidases from basidiomycetous fungi (Table 2).

Table 2. Apparent kinetic constants $\left(K_{\mathrm{M}}, k_{\mathrm{cat}}\right.$, and $\left.k_{\text {cat }} / K_{\mathrm{M}}\right)$ of purified $\mathrm{XgrDyP}$ for the substrates ABTS, 2,6-DMP, RBlue5, and $\mathrm{Mn}^{2+}$.

\begin{tabular}{cccc}
\hline Substrate & $\boldsymbol{k}_{\text {cat }}\left(\mathbf{s}^{-\mathbf{1}}\right)$ & $\boldsymbol{K}_{\mathbf{M}}(\boldsymbol{\mu M})$ & $\boldsymbol{k}_{\text {cat }} / \boldsymbol{K}_{\mathbf{M}}\left(\mathbf{s}^{-\mathbf{1}} \mathbf{m M}^{-\mathbf{1}}\right)$ \\
\hline ABTS & 12 & 41 & 287 \\
2,6-DMP & 29 & 12 & 2499 \\
RBlue5 & 20 & 41 & 495 \\
Mn $^{2+}$ & 0.4 & 49 & 8 \\
\hline
\end{tabular}




\subsection{XgrDyP Encoding Genes and Their Deduced Protein Sequences}

A custom blast search using reference sequences from B. adusta and Pseudomonas aeruginosa DyPs indicated the presence of three DyP-encoding genes $(g 488, g 9177$, and g1956) in the X. grammica genome (Figure 5).

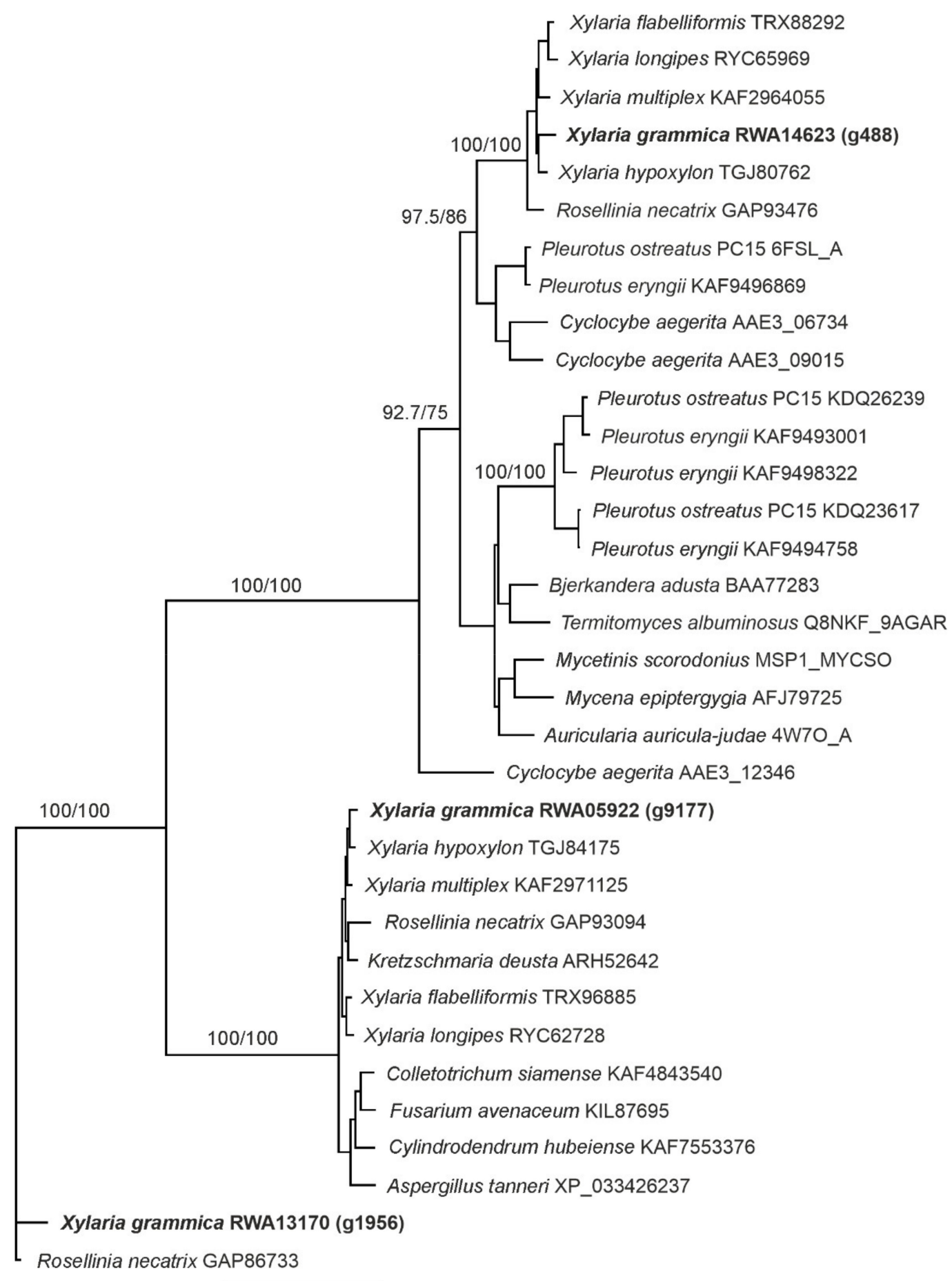

2.0

Figure 5. Maximum likelihood phylogenetic tree (log-likelihood: -18,869.58452) using a DyP protein sequence alignment in PhyML 3.0 [35] with the following model: LG+I+G. Branch support was estimated using a bootstrap approach, first value: 2000 replicates of neighbor-joining trees using Jukes-Cantor distances, second value: 100 replicates of the maximum likelihood approach using LG + I + G model. 
The properties of the three genes (e.g., ORF and the number of introns) and their deduced putative protein sequences (protein length, molecular weight, etc.) are given in Supplementary Table S1. The two genes $g 488$ and $g 9177$ had the typical conserved heme-binding motif G-X-X-D-G [5]; by contrast, g1956 had an unusual G-X-X-D-H motif (Supplementary Figures S1-S3). By peptide de novo sequencing, it turned out that the purified $\mathrm{XgrDyP}$ is a product of $g 488$ (Figure 5). The deduced protein from DyP $g 488$ contained 493 amino acids, had a hypothetical molecular mass of $53.9 \mathrm{kDa}$ and a pI of 6.5. No signal peptide was predicted for all three DyP sequences (Supplementary Table S1).

The phylogenetic tree (Figure 5) contains sequences from 34 selected fungal DyPs from basidio- and ascomycetes. It demonstrates that the $\mathrm{XgrDyPs}$ encoded by three genes belong to different clades. For instance, the gene encoding the purified protein $g 488$ matches within group ' $\mathrm{D}$ ', in which all so far characterized basidiomyceteous DyPs (e.g., DyPs from B. adusta, BadDyP and A. auricula-judae, AauDyP) can be grouped [22] or within the new group ' $V$ ' according to Yoshida and Sugano [21].

The XgrDyP encoded by $g 488$ showed the highest homologies to hypothetical DyPs from phylogenetically related ascomycetes (e.g., to $79 \%$ to Xylaria hypoxylon and to $78 \%$ to Xylaria multiplex). The highest homologies to characterized DyPs were found for the recombinant protein from P. ostreatus DyP4 (rPosDyP4; 44\%) and the wild-type proteins from B. adusta (BadDyP; 40\%) and A. auricula judae (AauDyP1; 38\%).

Gene $g 9177$ could be assigned to group ' $\mathrm{B}$ ' [22] or the new group ' $\mathrm{P}$ ' according to Yoshida and Sugano [21], which mainly contains bacterial DyPs or encapsulin encoding sequences and a putative DyP from the wood-dwelling ascomycete X. multiplex (KAF2971125). With the latter, $g 9177$ shares $85 \%$ homology. The gene $g 1956$, however, proved to be an unusual gene encoding probably for both a $\mathrm{DyP}$ and a pyruvate-formate lyase-like domain (similar genes are deposited in NCBI under GAW13804.1 and GAP86733.1). Moreover, it groups within a cluster of four putative ascomyceteous DyPs with one, e.g., from Rosellina necatrix (with 78\% homology; Figure 5).

\section{Discussion}

\subsection{Production of a New DyP-Type Peroxidase from the Ascomycete X. grammica}

Fungal DyPs have been reported from more than 100 basidiomycetous and ascomycetous species with about 400 and 200 individual sequences, respectively. Of them, nine proteins from seven organisms have been characterized so far (B. adusta, M. scorodonius, Termitomyces albuminosus (formerly known as G. candidum), A. auricula-judae, E. glandulosa, M. epipterygia, I. lacteus; [37]); moreover, there are numerous reports on intracellular bacterial DyPs, which, however, differ considerably from their fungal counterparts [21].

The conditions under which DyPs are expressed and secreted are not yet fully understood $[37,38]$. The physiological function of this enzyme type also remains unclear. The induction of DyPs under lab-scale conditions is usually accomplished by using complex plant-based growth media (containing a variety of plant ingredients including secondary metabolites). The fungal DyPs that have been characterized so far (only nine representatives) can be produced in soybean meal suspension or in diluted 'organic tomato juice' supplemented with 'elicitors' such as phenols or terpenoids (as shown for the DyPs or M. epipterygia and E. glandulosa; [9]). X. grammica is the first ascomycetous fungus that has been shown to produce a wild-type DyP. Enzyme levels were up to $\sim 750 \mathrm{U} \mathrm{L}^{-1}$, which is sufficient for protein purification and characterization studies. The enzyme titers secreted by the fungus correspond to medium activity levels. In contrast, several other fungi have been found to secrete just low amounts of $\operatorname{DyP}\left(<100 \mathrm{U} \mathrm{L}^{-1}\right)$, which is sometimes difficult to verify and usually not sufficient to serve as starting point for purification studies (e.g., DyPs of Mycena haematopus and Stropharia rugosoannulata; [39]). On the other hand, there are a few fungi (species and strains) that secrete larger amounts of enzyme, enabling purification and subsequent characterization and application studies possible, e.g., A. auricula-judae with $\sim 8000 \mathrm{U} \mathrm{L}^{-1}$ DyP [8]. 


\subsection{Comparison of XgrDyP with Other Fungal DyP-Type Peroxidases}

The DyP of X. grammica was purified using FPLC protocols (AEX, SEC) similar to those that have already been successfully used to prepare other fungal wild-type DyPs (e.g., from A. auricula-judae, M. epipterygia, and E. glandulosa; $[8,9])$. Finally, one homogeneous $\mathrm{XgrDyP}$ fraction was obtained that could be used for enzyme characterization. All purified and characterized reference DyPs are of basidiomycetous origin and as of yet, there are no enzymes of this type available from the ascomycetes. The specific activity ( $51 \mathrm{U} \mathrm{mg}^{-1}$ with ABTS as substrate), molecular mass (49 $\mathrm{kDa})$, and spectroscopic absorbance maxima (with the characteristic Soret band at $406 \mathrm{~nm}$ ) of this ascomycetous DyP are in the range of data reported for its basidiomycetous counterparts (up to $469 \mathrm{U} \mathrm{mg}^{-1}, 43$ to $69 \mathrm{kDa}$, Soret bands between 405 and $407 \mathrm{~nm}$; [9]).

\subsection{Catalytic Properties of X. grammica DyP}

The substrate spectrum of $\mathrm{XgrDyP}$ is strongly indicative of its affiliation to the protein family of DyP-type peroxidases (including RBlue5 oxidation; [4]). Remarkably, the catalytic constants for certain substrates indicate that XgrDyP shares characteristics of both DyP-type peroxidases and high-redox potential class II PODs such as VP or MnP (e.g., from Pleurotus eryngii, P. ostreatus or B. adusta) or LiP (e.g., from P. chrysosporium). Thus, the $K_{M}$ values (affinities) for the oxidation of typical peroxidase substrates such as ABTS and 2,6-DMP by XgrDyP are in the same range as the values reported for two AauDyPs [8] and the oxidation of the non-phenolic aromatic substrate veratryl alcohol occur over the same range of $\mathrm{pHs}(\mathrm{pH}<3.0)$ as those reported for AauDyPs [9]. Furthermore, the affinities of $\mathrm{XgrDyP}$ to these 'classic' peroxidase substrates were higher than those described for the MnPs of P. ostreatus PosMnP3 and PosMnP6 (two short hybrid-type manganese peroxidases (hMnPs) that also oxidize, in addition to $\mathrm{Mn}^{2+}$, phenolics and ABTS [5]; $K_{\mathrm{M}}=778$ and $1020 \mu \mathrm{M}$, respectively for ABTS and $K_{\mathrm{M}}=59,000$ and $117,000 \mu \mathrm{M}$, respectively for 2,6-DMP). Moreover, the recombinant DyPs from P. ostreatus ( $\mathrm{rPosDyP} 1$ and 4 ) had much lower affinities for these typical peroxidase substrates $\left(K_{\mathrm{M}}=779\right.$ and $787 \mu \mathrm{M}$, respectively for ABTS and $K_{\mathrm{M}}=31,100$ and $126 \mu \mathrm{M}$, respectively, for 2,6-DMP; Supplementary Table S2) [12].

Interestingly, the ascomycetous DyP belongs-from the biochemical point of view-to the small group of $\mathrm{Mn}^{2+}$-oxidizing DyPs, of which five representatives are so far known. Among them are a few bacterial representatives (from Pseudomonas fluorescens, $R$. jostii, and Amycolatopsis sp.; $[11,40,41]$ and only two recombinant basidiomycetous proteins from P. osteratus (rPosDyP1 and 4) expressed in E. coli [12]). The affinity of XgrDyP for $\mathrm{Mn}^{2+}$ ions $\left(K_{\mathrm{M}}=49 \mu \mathrm{M}\right)$ is in the typical range of 'classic' MnPs (e.g., from P. chrysosporium, 4-9 $\mu \mathrm{M}$, [42]; Agrocybe praecox and Stropharia coronilla, 17 and $12 \mu \mathrm{M}$, respectively, [43]; P. ostreatus, $10 \mu \mathrm{M}$, [44]; as well as for VPs (e.g., from P. eryngii, 12-20 $\mu \mathrm{M}$; [45])). On the other hand, the turnover numbers ( $k_{\mathrm{cat}}$ ) of 'true' MnPs are (e.g., $150 \mathrm{~s}^{-1}$ for B. adusta, [46] and or $218 \mathrm{~s}^{-1}$ for P. chrysosporium, [47]) are two orders of magnitude higher than the $k_{\text {cat }}$ values determined for the ascomycetous DyP $\left(k_{\text {cat }}=0.4 \mathrm{~s}^{-1}\right)$. The Michaelis-Menten constants of the $\mathrm{Mn}^{2+}$-oxidizing fungal DyPs (rPosDyP1 and 4$)$ are much higher $\left(K_{\mathrm{M}}=2780\right.$ and $286 \mu \mathrm{M}$, respectively) than that of $\mathrm{XgrDyP}$, but the catalytic efficiency, at least of $\mathrm{rPosDyP} 4$, is about one magnitude higher $\left(196 \mathrm{~s}^{-1} \mathrm{mM}^{-1}\right)$ than that calculated for the $\mathrm{Xgr}$ DyP $\left(8 \mathrm{~s}^{-1} \mathrm{mM}^{-1}\right)$. All these findings indicate that $\mathrm{Mn}^{2+}$ ions bind with high affinity to the $\mathrm{XgrDyP}$ protein (very probably at suitable acidic amino acid, i.e., aspartates and glutamates) but their subsequent oxidation into reactive $\mathrm{Mn}^{3+}$ may proceed with much lower efficiency compared to MnPs and VPs. $\mathrm{Mn}^{2+}$ oxidation by $\mathrm{XgrDyP}$ proceeded most effectively under acidic $\mathrm{pH}$ conditions, which is also a characteristic feature of all 'classic' MnPs and comparable to the respective activities of certain recombinant DyPs from P. ostreatus (e.g., at $\mathrm{pH} 4.5$; [12]).

Generally, the ability to efficiently oxidize $\mathrm{Mn}^{2+}$ ions is a specific catalytic property of certain class II PODs (MnP, hMnP (hybrid-type MnP), and VP). These enzyme types are exclusively found in Basidiomycota (e.g., in the families Polyporaceae, Corticiaceae, 
Pleurotaceae, Agaricaceae, or Strophariaceae) causing white-rot or accomplishing soil-litter decomposition $[5,48]$. The high abundance of these peroxidases among saprotrophic basidiomycetes and their ubiquitous presence in natural deadwood strongly suggests that the oxidation of manganese $\left(\mathrm{Mn}^{2+} \rightarrow \mathrm{Mn}^{3+}\right)$ is one of the key steps in lignin decomposition [5,49-51].

In contrast, according to comprehensive genomic data, wood-inhabiting Ascomycota (e.g., Xylariaceae) are obviously lacking MnPs and other high-redox potential class II PODs [52-54]. In this context, the finding of an Mn-oxidizing ascomycetous DyP is remarkable, and could explain why some of these fungi (e.g., X. grammica or Xylaria polymorpha) can nevertheless degrade and mineralize lignin (e.g., $\beta-O-4$ dimers such as adlerol), at least to some extent $[8,23,55]$. In other words, certain DyPs may fulfill the roles of MnPs/VP in some ascomycetous fungi, for example, in those species causing a strong soft rot [12].

\subsection{Structural Aspects}

As other peroxidases of this type, $\mathrm{XgrDyP} g 488$ has a characteristic heme environment comparable with that of some basidiomycetous DyPs (e.g., sequence identity to AauDyP1 $38 \%,[6,18]$ and to rPosDyP4 44\%, [56]). It contains a proximal histidine (His336), which is structurally homologous to His361 and His334 in rPosDyP1 and 4, respectively [12], as well as to His306 and His304 in BadDyP and AauDyP, respectively [18]. The distal heme environment of XgrDyP $g 488$ contains conserved amino acids that act as a proton acceptor (aspartate, Asp192) and charge stabilizer (arginine, Arg359; [5,6,18]) as well as the co-substrate binding/guiding residues (phenylalanine/Phe390 and leucine/Leu388; [37]). The entrance to the heme channel of $\mathrm{XgrDyP} g 488$ is characterized by the presence of an aspartate, an amino acid residue previously described for AauDyP1 as a "gatekeeper." Flipping of the Asp168 side chain of AauDyP1 results in molecular movement and thus some widening of the heme entrance channel [18].

Identification of a hypothetical $\mathrm{Mn}^{2+}$ oxidation site in the hypothetical 3D structure of $\mathrm{XgrDyP} g 488$ was performed by high-resolution protein modeling using the C-I-Tasser webserver. The C-I-Tasser calculation identified rPosDyP4 (PDB: 6fsk) as the protein structure most closely resembling $\mathrm{XgrDyP}$, with a TM-score of 0.92 (data not shown). Therefore, the tertiary structure of recombinant $\mathrm{Mn}^{2+}$-oxidizing rPosDyP4 was used to construct the hypothetical 3D model of XgrDyP $g 488$.

In contrast to the $\mathrm{Mn}^{2+}$-binding amino acids in classical MnPs (e.g., from P. chrysosporium, PchMnP, [57]) which comprise carboxylic groups of mostly three acidic amino acids (i.e., glutamates or aspartates) and a heme propionate residue, no similar binding site could be detected in the hypothetical XgrDyP $g 488$ 3D protein structure (data not shown).

Fueyo et al. [56] identified an $\mathrm{Mn}^{2+}$ binding site on the surface of rPosDyP4 based on mutation studies. This consists of the four acidic amino acids (Asp215, Asp352, Asp345, Glu354) and Tyr339. The enzyme obviously uses an electron transfer mechanism ('electron hopping') from the glutamate (Glu345) to the heme via an aromatic residue (Tyr339, Figure 6A; [56]). In the case of XgrDyP, no similar surface-exposed $\mathrm{Mn}^{2+}$ oxidation site could be identified within the structure model. In the corresponding region, only two rather distantly related acidic amino acids are present (Glu353 and Asp347). Their probably coordinating carboxylates do not show a distinct orientation towards the protein surface and no aromatic amino acid is available for an electron transfer towards the heme (Figure 6B). 

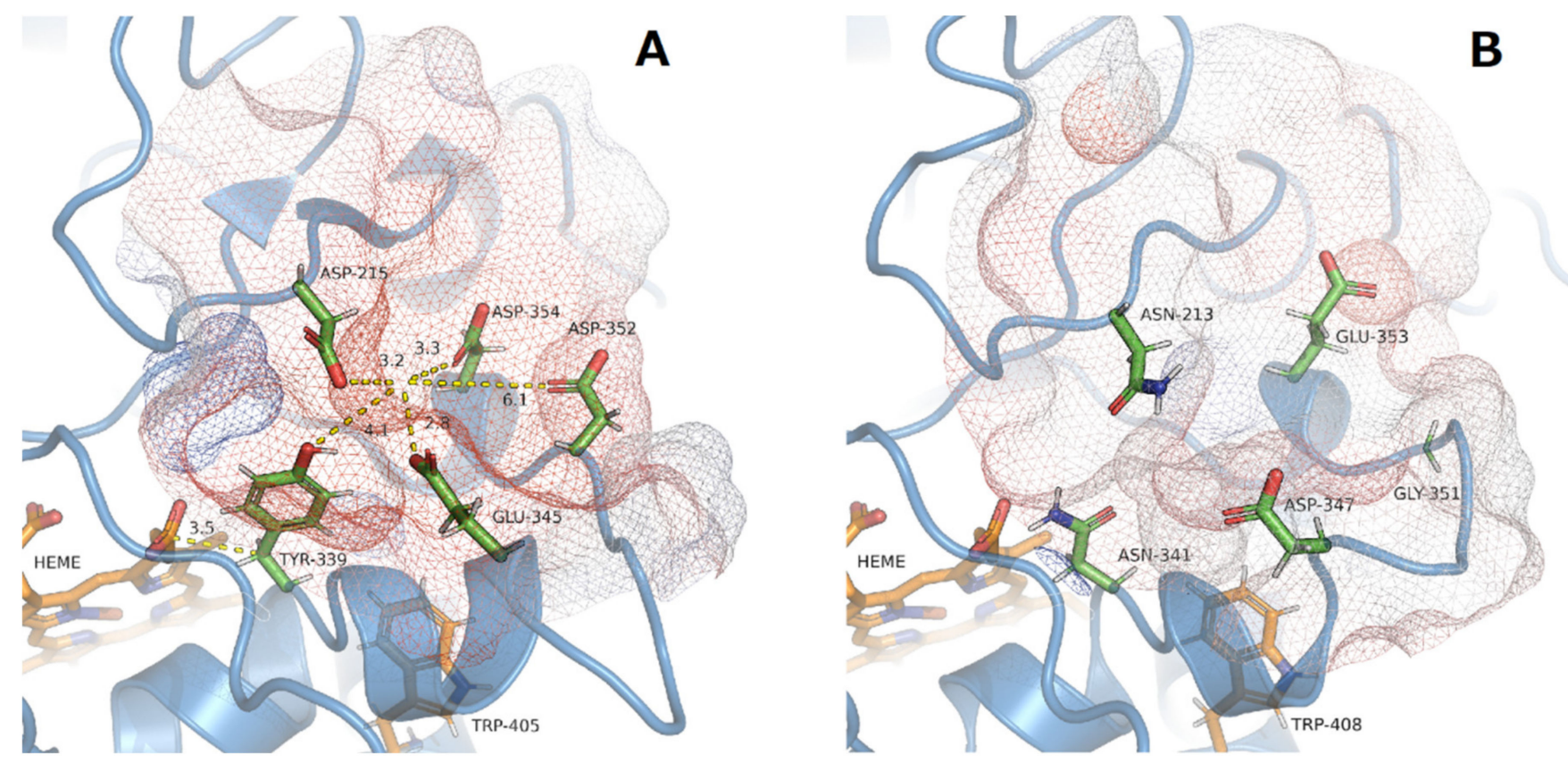

Figure 6. (A) Characterized $\mathrm{Mn}^{2+}$ binding site and distribution of the coordinating acid amino acids and the electron transferring Tyr339 in rPosDyP4 [56] (distances in $\AA$ are indicated yellow dotted lines) and (B) the corresponding analogous region in the hypothetical 3D structure of $\mathrm{XgrDyP} g 488$. The solvent excluded surface (SES) around the putative Mn ${ }^{2+}$ binding site is given as a colored mesh from blue to red according to the electrostatic charge distribution (blue-positive, red-negative) and is used to approximate the hypothetic $\mathrm{Mn}^{2+}$ position.

In addition, another potential $\mathrm{Mn}^{2+}$ binding site on the protein surface was described in the same rPosDyP4 and in the crystal structure of the $\mathrm{Mn}^{2+}$-oxidizing DyP2 of the bacterium Amycolatopsis sp. (AspDyP2; PDB: 4g2c). Again, these are nearby acidic and aromatic amino acids (Figure 7, e.g., Asp260, Asp275, Asp285, and Tyr190 in AspDyP2; [40,56]).

In the model structure of $\mathrm{XgrDyP} g 488$, a comparable region near the protein surface was detected. The $\mathrm{Mn}^{2+}$ ion could be coordinated by three acidic amino acids (Asp269 and 288, and Glu265; Figure 7A) and the oxidation may be supported by four aromatic amino acids (three Phe190, 264, and 188 and one Trp298), which act as partners for the electron transfer. The three Phe residues are in close proximity to each other (e.g., $2.4 \AA$ between Phe264 and 190) as well as to the heme center, making them suitable for electron transport. This protein environment is rather similar to the $\mathrm{Mn}^{2+}$ binding site postulated for the bacterial $A s p \mathrm{DyP} 2$. It is also interesting to note that the relevant acidic and aromatic amino acids are conserved in both bacterial and several fungal DyPs [56].

Finally, it should be mentioned again that the substrate oxidation site of $\mathrm{XgrDyP}$ g488 is putative and that the orientation and distances between the involved ligands and metal ions may alter during binding and/or catalysis (Figure 7A). Definite clarification of these points can be only achieved once the crystal structure of $\mathrm{XgrDyP}$ (encoded by g488) is solved, which will allow an analysis of the molecular architecture of the $\mathrm{Mn}^{2+}$ coordination sphere. 
A

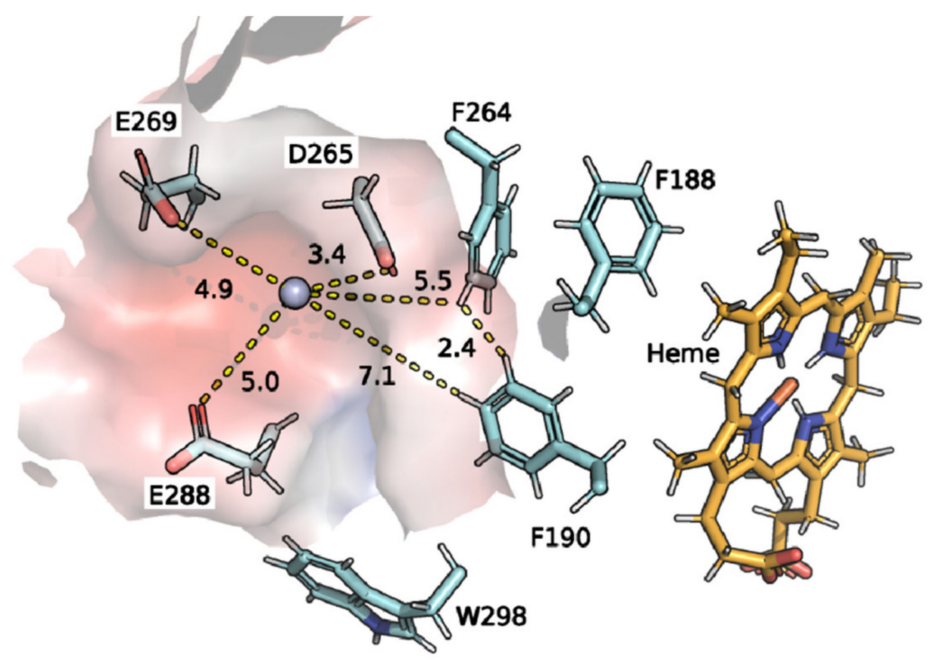

B
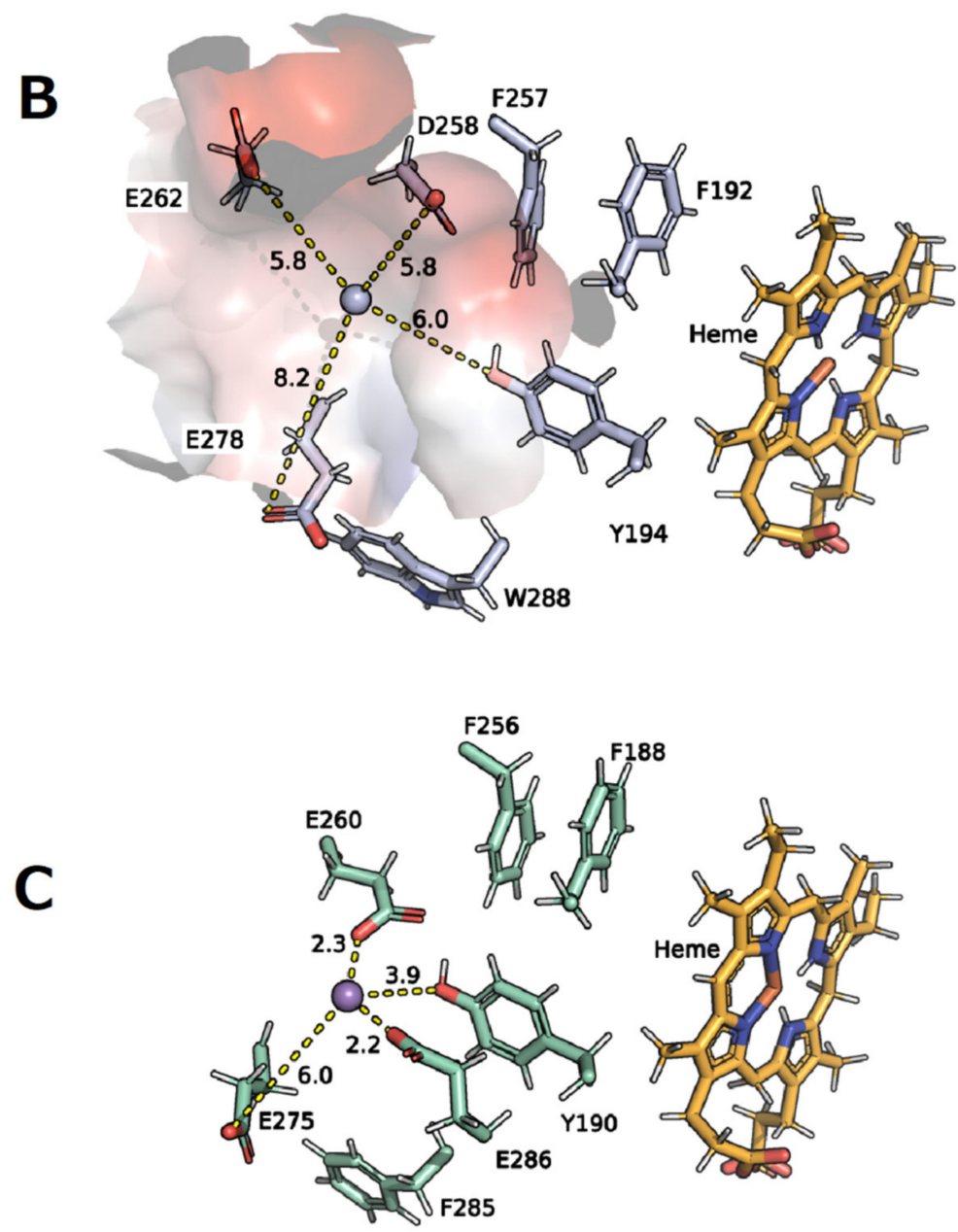

Figure 7. (A) Hypothetical $\mathrm{Mn}^{2+}$ binding site in the protein model of $\mathrm{XgrDyP} g 488$, in comparison to the characterized structures of the (B) fungal rPosDyP4 (PBD: 6fsk; [56]) and (C) the bacterial AspDyP2 (PBD: 4g2c).

\section{Conclusions}

In the future, recombinant expression studies, although challenging, will facilitate and improve the production of target heme peroxidases including DyPs. This, in turn, would be an important prerequisite for comprehensive protein structure-function and molecular engineering studies. Both approaches may help to identify catalytically relevant amino acids (e.g., for the binding and oxidation of $\mathrm{Mn}^{2+}$ by $\mathrm{XgrDyP}$ ). Whether the $\mathrm{Mn}^{2+}$ 
oxidizing capability of $\mathrm{Xgr}$ DyP really has physiological implications for wood and lignin degradation by Xylaria spp., remains unclear. Possibly, 'DyP-knock-out mutants' of $X$. grammica (obtainable using modern techniques of gene-editing such as CRISPR/Cas) will help to answer this important question.

Not least, testing the lignocellulose degrading activities of the XgrDyP and X. grammica will help to answer the ecologically and physiologically relevant question as to whether manganese oxidation is actually the basis of ligninolysis. In particular, evidence for a $\mathrm{DyP} / \mathrm{Mn}^{2+/ 3+}$-based depolymerization system would further improve our understanding of lignin degradation in nature and shed new light on the role of Ascomycota in this process.

Supplementary Materials: The following are available online at https:/ /www.mdpi.com/article/10 $.3390 / \mathrm{biom} 11091391 / \mathrm{s} 1$.

Author Contributions: C.L. and R.U. conceived and planned the experiments; V.K. carried out all experiments, data analysis and interpretation, supervised by R.U., C.L., E.B., H.K. and R.H. E.B. and H.K. supervised genome sequencing, annotation and assembling as well as the phylogenic analyses; N.J. carried out the proteome analysis and R.H. supported the protein modeling with C-I-TASSER; V.K. drafted the manuscript and C.L. provided critical revisions of the manuscript drafts and carried out the revision; M.H. acquired the funding of this work, supervised the overall study and supported manuscript writing by reviewing and editing. All authors have read and agreed to the published version of the manuscript.

Funding: This research was funded by German Exchange Service (Deutscher Akademischer Austauschservice; DAAD-91563642), BMBF (CEFOX-031B0831E, VnmDiv-031B0627) and PZ-Syn (22F241-03-FhG/005/001).

Institutional Review Board Statement: Not applicable.

Informed Consent Statement: Not applicable.

Data Availability Statement: Full data sets are available either in public data bases e.g., NCBI, PDB, in the Supplementary Materials (see the main text) or upon request from the corresponding author.

Acknowledgments: We acknowledge support by the German Exchange Service (Deutscher Akademischer Austauschservice; DAAD-91563642), BMBF (CEFOX-031B0831E, VnmDiv-031B0627) and PZ-Syn (22-F241-03-FhG/005/001).

Conflicts of Interest: The authors declare no conflict of interest.

\section{References}

1. Kim, S.J.; Ishikawa, K.; Hirai, M.; Shoda, M. Characteristics of a newly isolated fungus, Geotrichum candidum Dec 1, which decolorizes various dyes. J. Ferment. Bioeng. 1995, 79, 601-607. [CrossRef]

2. Kim, S.J.; Shoda, M. Purification and Characterization of a Novel Peroxidase from Geotrichum candidum Dec 1 Involved in Decolorization of Dyes. Appl. Environ. Microbiol. 1999, 65, 1029-1035. [CrossRef]

3. Sugano, Y.; Sasaki, K.; Shoda, M. cDNA cloning and genetic analysis of a novel decolorizing enzyme, peroxidase gene dyp from Geotrichum candidum Dec 1. J. Biosci. Bioeng. 1999, 87, 411-417. [CrossRef]

4. Sugano, Y.; Matsushima, Y.; Tsuchiya, K.; Aoki, H.; Hirai, M.; Shoda, M. Degradation pathway of an anthraquinone dye catalyzed by a unique peroxidase DyP from Thanatephorus cucumeris Dec 1. Biodegradation 2009, 20, 433-440. [CrossRef]

5. Hofrichter, M.; Ullrich, R.; Pecyna, M.J.; Liers, C.; Lundell, T. New and classic families of secreted fungal heme peroxidases. Appl. Microbiol. Biotechnol. 2010, 87, 871-897. [CrossRef] [PubMed]

6. Strittmatter, E.; Wachter, S.; Liers, C.; Ullrich, R.; Hofrichter, M.; Plattner, D.A.; Piontek, K. Radical formation on a conserved tyrosine residue is crucial for DyP activity. Arch. Biochem. Biophys. 2013, 537, 161-167. [CrossRef]

7. Scheibner, M.; Hülsdau, B.; Zelena, K.; Nimtz, M.; De Boer, L.; Berger, R.G.; Zorn, H. Novel peroxidases of Marasmius scorodonius degrade $\beta$-carotene. Appl. Microbiol. Biotechnol. 2008, 77, 1241-1250. [CrossRef]

8. Liers, C.; Bobeth, C.; Pecyna, M.; Ullrich, R.; Hofrichter, M. DyP-like peroxidases of the jelly fungus Auricularia auricula-judae oxidize nonphenolic lignin model compounds and high-redox potential dyes. Appl. Microbiol. Biotechnol. 2010, 85, 1869-1879. [CrossRef] [PubMed]

9. Liers, C.; Pecyna, M.J.; Kellner, H.; Worrich, A.; Zorn, H.; Steffen, K.T.; Hofrichter, M.; Ullrich, R. Substrate oxidation by dye-decolorizing peroxidases (DyPs) from wood- and litter-degrading agaricomycetes compared to other fungal and plant heme-peroxidases. Appl. Microbiol. Biotechnol. 2012, 97, 5839-5849. [CrossRef] 
10. Rahmanpour, R.; Rea, D.; Jamshidi, S.; Fülöp, V.; Bugg, T.D. Structure of Thermobifida fusca DyP-type peroxidase and activity towards Kraft lignin and lignin model compounds. Arch. Biochem. Biophys. 2016, 594, 54-60. [CrossRef] [PubMed]

11. Roberts, J.N.; Singh, R.; Grigg, J.C.; Murphy, M.E.P.; Bugg, T.D.H.; Eltis, L.D. Characterization of Dye-Decolorizing Peroxidases from Rhodococcus jostii RHA1. Biochemistry 2011, 50, 5108-5119. [CrossRef]

12. Fernández-Fueyo, E.; Linde, D.; Almendral, D.; López-Lucendo, M.F.; Ruiz-Dueñas, F.J.; Martínez, A.T. Description of the first fungal dye-decolorizing peroxidase oxidizing manganese(II). Appl. Microbiol. Biotechnol. 2015, 99, 8927-8942. [CrossRef] [PubMed]

13. Sugano, Y.; Muramatsu, R.; Ichiyanagi, A.; Sata, T.; Shoda, M. DyP, a unique dye-decolorizing peroxidase, represents a novel heme peroxidase family: ASP171 replaces the distal histidine of classical peroxidases. J. Biol. Chem. 2007, 282, 36652-36658. [CrossRef]

14. Linde, D.; Coscolín, C.; Liers, C.; Hofrichter, M.; Martínez, A.T.; Ruiz-Dueñas, F.J. Heterologous expression and physico-chemical characterization of a fungal dye-decolorizing peroxidase from Auricularia auricula-judae. Protein Expr. Purif. 2014, 103, 28-37. [CrossRef] [PubMed]

15. Linde, D.; Pogni, R.; Cañellas, M.; Lucas, F.; Guallar, V.; Baratto, M.C.; Sinicropi, A.; Sáez-Jiménez, V.; Coscolín, C.; Romero, A.; et al. Catalytic surface radical in dye-decolorizing peroxidase: A computational, spectroscopic and site-directed mutagenesis study. Biochem. J. 2015, 466, 253-262. [CrossRef]

16. Yoshida, T.; Tsuge, H.; Konno, H.; Hisabori, T.; Sugano, Y. The catalytic mechanism of dye-decolorizing peroxidase DyP may require the swinging movement of an aspartic acid residue. FEBS J. 2011, 278, 2387-2394. [CrossRef]

17. Yoshida, T.; Tsuge, H.; Hisabori, T.; Sugano, Y. Crystal structures of dye-decolorizing peroxidase with ascorbic acid and 2,6-dimethoxyphenol. FEBS Lett. 2012, 586, 4351-4356. [CrossRef] [PubMed]

18. Strittmatter, E.; Liers, C.; Ullrich, R.; Wachter, S.; Hofrichter, M.; Plattner, D.A.; Piontek, K. First crystal structure of a fungal high-redox potential dye-decolorizing peroxidase substrate interaction sites and long-range electron transfer. J. Biol. Chem. 2013, 288, 4095-4102. [CrossRef]

19. Mitchell, A.; Chang, H.Y.; Daugherty, L.; Fraser, M.; Hunter, S.; López, R.; McAnulla, C.; McMenamin, C.; Nuka, G.; Pesseat, S.; et al. The InterPro protein families database: The classification resource after 15 years. Nucleic Acids Res. 2015, 43, D213-D221. [CrossRef]

20. Van Bloois, E.; Pazmiño, D.E.T.; Winter, R.T.; Fraaije, M.W. A robust and extracellular heme-containing peroxidase from Thermobifida fusca as prototype of a bacterial peroxidase superfamily. Appl. Microbiol. Biotechnol. 2009, 86, 1419-1430. [CrossRef]

21. Yoshida, T.; Sugano, Y. A structural and functional perspective of DyP-type peroxidase family. Arch. Biochem. Biophys. 2015, 574, 49-55. [CrossRef]

22. Zámocký, M.; Obinger, C. Molecular phylogeny of heme peroxidases. In Biocatalysis Based on Heme Peroxidases, 1st ed.; Torres, E., Ayala, M., Eds.; Springer: Berlin/Heidelberg, Germany, 2010; pp. 7-35.

23. Salvachúa, D.; Martínez, A.T.; Tien, M.; López-Lucendo, M.F.; García, F.; Ríos, V.D.L.; Martínez, M.J.; Prieto, A. Differential proteomic analysis of the secretome of Irpex lacteus and other white-rot fungi during wheat straw pretreatment. Biotechnol. Biofuels 2013, 6, 115. [CrossRef]

24. Sugawara, K.; Igeta, E.; Amano, Y.; Hyuga, M.; Sugano, Y. Degradation of antifungal anthraquinone compounds is a probable physiological role of DyP secreted by Bjerkandera adusta. AMB Express 2019, 9, 1-8. [CrossRef] [PubMed]

25. Kellner, H.; Luis, P.; Pecyna, M.J.; Barbi, F.; Kapturska, D.; Krüger, D.; Zak, D.R.; Marmeisse, R.; Vandenbol, M.; Hofrichter, M. Widespread Occurrence of Expressed Fungal Secretory Peroxidases in Forest Soils. PLoS ONE 2014, 9, e95557. [CrossRef] [PubMed]

26. Büttner, E.; Kimani, V.W.; Kellner, H.; Hofrichter, M.; Liers, C. Genome Sequence of the Versatile Deadwood Decomposer Xylaria grammica IHIA82. Microbiol. Resour. Announc. 2021, 10, 1306-1320. [CrossRef]

27. Gröbe, G.; Ullrich, R.; Pecyna, M.J.; Kapturska, D.; Friedrich, S.; Hofrichter, M.; Scheibner, K. High-yield production of aromatic peroxygenase by the agaric fungus Marasmius rotula. AMB Express 2011, 1, 31. [CrossRef] [PubMed]

28. Kiebist, J.; Schmidtke, K.-U.; Zimmermann, J.; Kellner, H.; Jehmlich, N.; Ullrich, R.; Zänder, D.; Hofrichter, M.; Scheibner, K. A Peroxygenase from Chaetomium globosum Catalyzes the Selective Oxygenation of Testosterone. ChemBioChem 2017, 18, 563-569. [CrossRef] [PubMed]

29. Wolfenden, B.S.; Willson, R.L. Radical-cations as reference chromogens in kinetic studies of one-electron transfer reactions: Pulse radiolysis studies of 2,2'-azinobis-(3-ethylbenzthiazoline-6-sulphonate). J. Chem. Soc. Perkin. Trans. 1982, 2, 805-812. [CrossRef]

30. Wariishi, H.; Valli, K.; Gold, M. Manganese(II) oxidation by manganese peroxidase from the basidiomycete Phanerochaete chrysosporium. Kinetic mechanism and role of chelators. J. Biol. Chem. 1992, 267, 23688-23695. [CrossRef]

31. Bradford, M.M. A rapid and sensitive method for the quantitation of microgram quantities of protein utilizing the principle of protein-dye binding. Anal. Biochem. 1976, 72, 248-254. [CrossRef]

32. Laemmli, U.K. Cleavage of Structural Proteins during the Assembly of the Head of Bacteriophage T4. Nature 1970, 227, 680-685. [CrossRef]

33. Bollag, J.-M.; Sjoblad, R.D.; Liu, S.-Y. Characterization of an enzyme from Rhizoctonia praticola which polymerizes phenolic compounds. Can. J. Microbiol. 1979, 25, 229-233. [CrossRef] 
34. Shimokawa, T.; Hirai, M.; Shoda, M.; Sugano, Y. Efficient Dye Decolorization and Production of Dye Decolorizing Enzymes by the Basidiomycete Thanatephorus cucumeris Dec 1 in a Liquid and Solid Hybrid Culture. J. Biosci. Bioeng. 2008, 106, $481-487$. [CrossRef] [PubMed]

35. Guindon, S.; Dufayard, J.-F.; Lefort, V.; Anisimova, M.; Hordijk, W.; Gascuel, O. New Algorithms and Methods to Estimate Maximum-Likelihood Phylogenies: Assessing the Performance of PhyML 3.0. Syst. Biol. 2010, 59, 307-321. [CrossRef]

36. Zheng, W.; Zhang, C.; Li, Y.; Pearce, R.; Bell, E.W.; Zhang, Y. Folding non-homologous proteins by coupling deep-learning contact maps with I-TASSER assembly simulations. Cell Rep. Methods 2021, 1, 100014. [CrossRef] [PubMed]

37. Pecyna, M.J. Molekularbiologische Charakterisierung von Häm-Thiolat-und DyP-Type-Peroxidasen Ausgewählter Basidiomyceten. Ph.D. Thesis, Technical University Dresden, Dresden, Germany, 2015.

38. Hofrichter, M.; Kellner, H.; Pecyna, M.J.; Ullrich, R. Fungal Unspecific Peroxygenases: Heme-Thiolate Proteins That Combine Peroxidase and Cytochrome P450 Properties. In Advances in Experimental Medicine and Biology; Springer: Berlin/Heidelberg, Germany, 2015; Volume 851, pp. 341-368.

39. Liers, C.; Arnstadt, T.; Ullrich, R.; Hofrichter, M. Patterns of lignin degradation and oxidative enzyme secretion by different woodand litter-colonizing basidiomycetes and ascomycetes grown on beech-wood. FEMS Microbiol. Ecol. 2011, 78, 91-102. [CrossRef] [PubMed]

40. Brown, M.E.; Barros, T.; Chang, M.C.Y. Identification and characterization of a multifunctional dye peroxidase from a lig-ninreactive bacterium. ACS Chem. Biol. 2012, 7, 2074-2081. [CrossRef]

41. Rahmanpour, R.; Bugg, T.D. Characterisation of Dyp-type peroxidases from Pseudomonas fluorescens Pf-5: Oxidation of Mn(II) and polymeric lignin by Dyp1B. Arch. Biochem. Biophys. 2015, 574, 93-98. [CrossRef]

42. Pease, E.A.; Tien, M. Heterogeneity and regulation of manganese peroxidases from Phanerochaete chrysosporium. J. Bacteriol. 1992, 174, 3532-3540. [CrossRef]

43. Steffen, K.T.; Hatakka, A.; Hofrichter, M. Degradation of humic acids by the litter-decomposing basidiomycete Collybia dry-ophila. Appl. Environ. Microbiol. 2002, 68, 3442-3448. [CrossRef]

44. Sarkar, S.; Martínez, A.T.; Martínez, M.J. Biochemical and molecular characterization of a manganese peroxidase isoenzyme from Pleurotus ostreatus. Biochim. Biophys. Acta Protein Struct. Mol. Enzym. 1997, 1339, 23-30. [CrossRef]

45. Martinez, M.J.; Ruiz-Duenas, F.J.; Guillen, F.; Martínez, A.T. Purification and Catalytic Properties of Two Manganese Peroxidase Isoenzymes from Pleurotus eryngii. JBIC J. Biol. Inorg. Chem. 1996, 237, 424-432. [CrossRef] [PubMed]

46. Wang, Y.; Vazquez-Duhalt, R.; Pickard, M.A. Purification, characterization, and chemical modification of manganese perox-idase from Bjerkandera adusta UAMH 8258. Curr. Microbiol. 2002, 45, 77-87. [CrossRef] [PubMed]

47. Giardina, P.; Palmieri, G.; Fontanella, B.; Rivieccio, V.; Sannia, G. Manganese Peroxidase Isoenzymes Produced by Pleurotus ostreatus Grown on Wood Sawdust. Arch. Biochem. Biophys. 2000, 376, 171-179. [CrossRef] [PubMed]

48. Ruiz-Dueñas, F.J.; Martínez, Á.T. Microbial degradation of lignin: How a bulky recalcitrant polymer is efficiently recycled in nature and how we can take advantage of this. Microb. Biotechnol. 2009, 2, 164-177. [CrossRef]

49. Hofrichter, M. Review: Lignin conversion by manganese peroxidase (MnP). Enzym. Microb. Technol. 2002, 30, 454-466. [CrossRef]

50. Arnstadt, T.; Hoppe, B.; Kahl, T.; Kellner, H.; Krüger, D.; Bässler, C.; Bauhus, J.; Hofrichter, M. Patterns of laccase and peroxidases in coarse woody debris of Fagus sylvatica, Picea abies and Pinus sylvestris and their relation to different wood parameters. Eur. J. For. Res. 2015, 135, 109-124. [CrossRef]

51. Noll, L.; Leonhardt, S.; Arnstadt, T.; Hoppe, B.; Poll, C.; Matzner, E.; Hofrichter, M.; Kellner, H. Fungal biomass and extra-cellular enzyme activities in coarse woody debris of 13 tree species in the early phase of decomposition. For. Ecol. Manag. 2016, 378, 181-192. [CrossRef]

52. Büttner, E.; Gebauer, A.M.; Hofrichter, M.; Liers, C.; Kellner, H. Draft Genome Sequence of the Wood-Degrading Ascomycete Kretzschmaria deusta DSM 104547. Genome Announc. 2017, 5, e01076-17. [CrossRef]

53. Büttner, E.; Gebauer, A.M.; Hofrichter, M.; Liers, C.; Kellner, H. Draft Genome Sequence of Scytalidium lignicola DSM 105466, a Ubiquitous Saprotrophic Fungus. Microbiol. Resour. Announc. 2018, 7, e01208-18. [CrossRef]

54. Büttner, E.; Liers, C.; Gebauer, A.M.; Collemare, J.; Navarro, J.; Hofrichter, M.; Kellner, H. Draft Genome Sequence of the Wood-Staining Ascomycete Chlorociboria aeruginascens DSM 107184. Microbiol. Resour. Announc. 2019, 8, e00249-19. [CrossRef] [PubMed]

55. Liers, C.; Ullrich, R.; Steffen, K.T.; Hatakka, A.; Hofrichter, M. Mineralization of 14C-labelled synthetic lignin and extracellular enzyme activities of the wood-colonizing ascomycetes Xylaria hypoxylon and Xylaria polymorpha. Appl. Microbiol. Biotechnol. 2005, 69, 573-579. [CrossRef]

56. Fernández-Fueyo, E.; Davó-Siguero, I.; Almendral, D.; Linde, D.; Baratto, M.C.; Pogni, R.; Romero, A.; Guallar, V.; Martínez, A.T. Description of a Non-Canonical Mn(II)-Oxidation Site in Peroxidases. ACS Catal. 2018, 8, 8386-8395. [CrossRef]

57. Sundaramoorthy, M.; Kishi, K.; Gold, M.H.; Poulos, T.L. The crystal structure of manganese peroxidase from Phanerochaete chrysosporium at 2.06-A resolution. J. Biol. Chem. 1994, 269, 32759-32767. [CrossRef] 